\title{
AVALIAÇÃO DO ESTADO NUTRICIONAL DA VIDEIRA 'ITÁLIA' NA REGIÃO DE JALES, SP, USANDO O SISTEMA INTEGRADO DE DIAGNOSE E RECOMENDAÇÃO ${ }^{1}$
}

\author{
MAURILO MONTEIRO TERRA ${ }^{2,3}$, MARSIA ANTONIETA SOUZA GUILHERME ${ }^{4}$, WAGNER RODRIGUES DOS SAN- \\ TOS $^{4}$, ERASMO JOSÉ PAIOLI-PIRES ${ }^{2,3}$, CELSO VALDEVINO POMMER ${ }^{2,3}$, RENATO VASCONCELOS BOTELHO ${ }^{4}$
}

RESUMO - O objetivo deste trabalho foi a avaliação do estado nutricional da videira 'Itália' na região de Jales, SP, Brasil, utilizando o DRIS. O levantamento nutricional foi realizado em 20 vinhedos em produção, submetidos a práticas culturais semelhantes. A coleta de amostras de folhas foi feita em três estágios de desenvolvimento da planta a saber: no florescimento, com frutos entre ervilha e meia baga e no início da maturação dos frutos. Nessa avaliação concluiu-se que o método DRIS é adequado para a videira 'Itália', pois permitiu obter informações a respeito do melhor órgão e épocas de amostragem, desordens nutricionais e índices referenciais para balanço nutricional. O limbo foi considerado o melhor órgão para amostragem, pois seus índices de balanço nutricional estavam mais ajustados. Os estágios de florescimento e de início da maturação dos frutos foram considerados adequados para amostragem de folhas. Seis vinhedos foram considerados em equilíbrio nutricional, pois apresentaram produção superior à média de 27,3 t/ha e Índice de Balanço Nutricional (IBN) igual a 11. Os 20 vinhedos amostrados foram considerados adequados para o cálculo das normas. Finalmente, o DRIS permitiu determinar os vinhedos que, em geral, apresentavam deficiência de potássio, magnésio, fósforo e enxofre, e excesso de cobre.

Termos para indexação: videira, Itália, nutrição, DRIS.

\section{EVALUATION OF THE NUTRITIONAL CONDITION OF ITALIA GRAPEVINE IN THE REGION OF JALES, SP, USING THE DIAGNOSIS AND RECOMMENDATION INTEGRATED SYSTEM}

\begin{abstract}
This work aimed to evaluate the nutritional condition of Italia grapevine in the region centered at Jales, SP, Brazil, using the DRIS. The nutritional survey was carried out in twenty vineyards by collecting leaf samples at three different developing phases: at bloom, in fruits between pea and half-berry, and at the begining of fruit maturation. DRIS was shown to be useful for 'Itália' grapevine. Leaf blade was considered the best organ for sampling because its nutritional balance indexes were more adjusted. The blooming and veraison were considered the suitable times for grapevine leaf sampling. Six vineyards were considered nutritionally balanced, with a produtivity above average of $27.3 \mathrm{t} / \mathrm{ha}$. The DRIS allowed the determination of vineyards which usually presented a deficiency of potassium, magnesium, phosphorus, and sulfur and excess of cooper.
\end{abstract}

Index terms: grapevine, Italia, nutrition, DRIS.

\section{INTRODUÇÃO}

A videira 'Itália' é um cultivar exigente do ponto de vista nutricional, tanto em qualidade como em quantidade de nutrientes. Por outro lado, a adubação deste cultivar, principalmente em regiões recém exploradas, como é o caso da região de Jales, tem sido feita de forma desequilibrada, gerando desordens nutricionais e auferindo prejuízos ao viticultor devido à queda na produção e na qualidade dos frutos, bem como onerando em demasia a cultura.

O DRIS foi originalmente proposto por Beaufils (1973) baseado nas relações de macro e micronutrientes como modelo para identificação de fatores limitantes de produtividade.Entretanto, com o tempo, tem-se mostrado muito mais eficiente como uma forma de interpretação de análise de planta do que como modelo de produtividade agrícola (Bataglia, 1989). Este método utiliza dados de concentração de nutrientes obtidos através da análise de folhas e avalia o estado nutricional da cultura pelas relações de nutrientes, consideradas um parâmetro importante para a cultura da videira, principalmente as relações $\mathrm{K} / \mathrm{Mg}, \mathrm{Ca} / \mathrm{Mg}$ e Ca/K .

Diversos trabalhos identificaram o método DRIS como uma alternativa para avaliar a nutrição das plantas.

Este trabalho teve por objetivo avaliar o estado nutricional da videira 'Itália' em três estágios de desenvolvimento, na região de Jales, SP, utilizando o DRIS, através da realização de um levantamento nutricional em vinhedos em produção.

\section{MATERIALEMÉTODOS}

Realizou-se o levantamento nutricional em 20 propriedades da região de Jales, Estado de São Paulo, situadas a 20¹6' S, 50³3' W e 483 m de altitude.

A escolha das propriedades foi ao acaso, e de cada propriedade foi selecionado um talhão de vinhedo em produção, com práticas culturais semelhantes. Nos talhões amostrados haviam 230 plantas espaçadas de $5 \mathrm{mx} 3 \mathrm{~m}$, com idade média de 5 anos e enxertadas sobre o porta-enxerto 420 -A.

De cada talhão foram selecionadas 20 plantas ao acaso, das quais foram coletadas cinco folhas por planta, totalizando 100 folhas por amostra. As folhas colhidas foram as recém-maduras de cada ramo produtivo, correspondendo a primeira folha oposta ao $1^{\circ}$ cacho, contandose a partir do ápice dos ramos. Das folhas coletadas, separaram-se imediatamente seus pecíolos e limbos, formando assim amostras distintas.

A coleta de folhas foi feita em três épocas distintas: a primeira no florescimento, quando ocorre um pico de concentração da maioria dos nutrientes nas folhas; a segunda quando as bagas estavam no estádio entre ervilha e meia-baga, fase intermediária; e no início do amolecimento das bagas realizou-se a terceira coleta, quando há maior estabilidade nos teores de nutrientes das folhas, permitindo assim maior amplitude na época de coleta.

As amostras de pecíolos e limbos foram processadas e analisadas separadamente quanto aos teores de $\mathrm{N}, \mathrm{P}, \mathrm{K}, \mathrm{Ca}, \mathrm{Mg}, \mathrm{S}, \mathrm{B}, \mathrm{Cu}, \mathrm{Fe}$, Mn e Zn, de acordo com Bataglia et al. (1983).

A interpretação dos resultados de análise foliar, considerandose a relação de nutrientes no limbo e no pecíolo e a produção da videira, foi feita aplicando-se o método DRIS.

Para o cálculo dos índices do DRIS, separou-se os vinhedos em duas classes: 1) População A - alta produtividade (27,3 t/ha ou mais) e 2) População B - baixa produtividade (menor que 27,3 t/ha ), em que o valor de 27,3 t/ha foi a média de produção encontrada entre os vinhedos amostrados e considerada alta para a cultura da videira na região.

Com as normas assim estabelecidas, calculou-se os índices DRIS e os índices de balanço nutricional (IBN) de acordo com a metodologia desenvolvida por Beaufils (1973) e também relatada por Bataglia \& Dechen (1986), utilizando-se a seguinte fórmula:

\footnotetext{
'(Trabalho 102/2002). Recebido: 24/06/2002. Aceito para publicação: 28/05/2003 ${ }^{2}$ Instituto Agronômico, Caixa Postal 28, 13001-970, Campinas,SP.

${ }^{3}$ Bolsista do CNPq.

${ }^{4}$ Bolsista da FAPESP.
} 
$\operatorname{Index} X=\frac{\sum\left[f\left(\frac{X}{A}\right)_{1} \frac{K}{C V(X / A)}+f\left(\frac{X}{B}\right){ }_{2} \frac{K}{C V(X / B)}+\cdots+f\left(\frac{X}{Z}\right)_{n} \frac{K}{C V(X / Z)}\right]-\sum\left[f\left(\frac{a}{X}\right){ }_{1} \frac{K}{C V(a / X)}+f\left(\frac{b}{X}\right){ }_{2} \frac{K}{C V(b / X)}+\cdots+f\left(\frac{z}{X}\right)_{m} \frac{K}{C V(z / X)}\right]}{n+m}$

IBN = S[índice $\mathrm{X}]$ em valores absolutos

onde

$\mathrm{A}, \mathrm{B}, \ldots \mathrm{Z}$ e $\mathrm{a}, \mathrm{b}, \ldots \mathrm{z}$ representam qualquer concentração de nutrientes possíveis de diagnose.

CV é o coeficiente de variação da relação na população não anormal

$\mathrm{K}$ é o coeficiente de sensibilidade, de valor arbitrário $=10$

$\mathrm{X} / \mathrm{A}, \mathrm{X} / \mathrm{B}, \ldots \mathrm{X} / \mathrm{Z}$ são as relações dos nutrientes na amostra

$\mathrm{n}-\mathrm{S} \mathrm{X} / \mathrm{A}+\mathrm{X} / \mathrm{B}+\ldots+\mathrm{X} / \mathrm{Z}$

$\mathrm{m}-\mathrm{S} \mathrm{a} / \mathrm{X}+\mathrm{b} / \mathrm{X}+\ldots+\mathrm{z} / \mathrm{X}$

Foram selecionados para os cálculos dos índices DRIS seis vinhedos com produtividades superiores a $27,3 \mathrm{t} / \mathrm{ha}$.

\section{RESULTADOS E DISCUSSÃO}

Beaufils (1973) referindo-se ao DRIS, observou que a escolha da população padrão, ou população de referência, é primordial para o sucesso do método e deve constituir-se de plantas não anormais, isto é, plantas que não tenham sido afetadas por condições anormais de cultivo.

A partir dos resultados das análises químicas das amostras de limbo e pecíolo dos vinhedos selecionados, correspondentes às três épocas de coletas, calculou-se as médias e os coeficientes de variação dos nutrientes no limbo e no pecíolo, conforme mostra a Tabela 1.

Levando-se em consideração que quanto maior o coeficiente de variação maiores são os desequilíbrios nutricionais, e que quando os valores de coeficiente de variação estão em torno ou acima de 50\%, esses desequilíbrios tornam-se preocupantes, pois podem limitar a produção; Admite-se que os vinhedos amostrados apresentam desordens nutricionais com relação ao fósforo, potássio, magnésio, enxofre e cobre. O estudo do estado nutricional usando o DRIS permite também determinar a ordem pela qual os nutrientes estão limitando a produção (Tabelas 2 a 7), através dos índices DRIS obtidos para cada nutriente. Os valores negativos indicam deficiências que diminuem à medida que os mesmos tendem a zero.

TABELA 1 - Concentração média dos nutrientes nos limbos e pecíolos de uva 'Itália', em função de épocas de amostragem.

\begin{tabular}{|c|c|c|c|c|c|c|c|c|c|c|c|c|}
\hline Amostra & Época & $\mathbf{N}$ & $\mathbf{P}$ & $\mathbf{K}$ & $\mathbf{C a}$ & $\mathbf{M g}$ & $\mathbf{S}$ & B & $\mathbf{C u}$ & $\mathbf{F e}$ & Mn & $\mathbf{Z n}$ \\
\hline \multirow{3}{*}{ Limbo } & & & & kg-- & -1 & --- & ----- & -...- & $---m g$ & g---- & ---- & ----- \\
\hline & Florescimento & 43,90 & 6,00 & 22,70 & 25,60 & 4,90 & 7,50 & 3,81 & 3,55 & 6,04 & 7,32 & 5,43 \\
\hline & CV $(\%)$ & 12,43 & 27,69 & 13,39 & 15,43 & 22,69 & 15,54 & 5,72 & 19,24 & 5,04 & 10,58 & 9,39 \\
\hline \multirow{10}{*}{ Pecíolo } & Ervilha & 38,20 & 6,00 & 22,70 & 21,80 & 4,40 & 7,10 & 3,76 & 3,79 & 6,76 & 7,21 & 5,30 \\
\hline & CV $(\%)$ & 9,83 & 34,74 & 15,10 & 15,01 & 19,73 & 28,57 & 4,08 & 50,61 & 12,48 & 8,46 & 12,52 \\
\hline & Amolecimento & 31,40 & 6,20 & 22,40 & 29,60 & 7,30 & 4,20 & 3,41 & 4,19 & 6,75 & 6,94 & 4,89 \\
\hline & CV $(\%)$ & 10,70 & 49,27 & 83,68 & 23,03 & 59,96 & 51,84 & 8,51 & 59,34 & 17,69 & 8,26 & 2,17 \\
\hline & Florescimento & 15,30 & 7,00 & 58,60 & 18,10 & 4,80 & 2,30 & 3,67 & 2,68 & 4,15 & 6,22 & 4,23 \\
\hline & CV $(\%)$ & 20,66 & 18,57 & 20,87 & 17,90 & 24,12 & 31,80 & 4,27 & 20,55 & 5,97 & 3,70 & 6,48 \\
\hline & Ervilha & 12,30 & 7,10 & 60,30 & 16,40 & 5,20 & 2,50 & 3,76 & 3,04 & 4,19 & 6,49 & 4,22 \\
\hline & $\mathrm{CV}(\%)$ & 20,55 & 18,59 & 23,84 & 19,46 & 16,61 & 21,50 & 4,88 & 33,20 & 10,51 & 5,29 & 5,90 \\
\hline & Amolecimento & 10,40 & 8,10 & 37,00 & 31,90 & 12,30 & 1,80 & 2,96 & 3,27 & 5,49 & 7,26 & 4,25 \\
\hline & $\mathrm{CV}(\%)$ & 15,12 & 36,38 & 36,45 & 18,02 & 41,14 & 48,11 & 10,94 & 52,25 & 15,04 & 10,58 & 15,75 \\
\hline
\end{tabular}

TABELA 2 - Produção, Índices DRIS, Índices de Balanço Nutricional (IBN) e Seqüência de deficiência a excesso nutricional para os vinhedos amostrados considerando limbo- $1^{\mathrm{a}}$ coleta (florescimento).

\begin{tabular}{|c|c|c|c|c|c|c|c|c|c|c|c|c|c|c|}
\hline \multirow[t]{2}{*}{ Vinhedo } & \multirow{2}{*}{$\begin{array}{l}\text { Prod. } \\
\text { t/ha }\end{array}$} & \multicolumn{11}{|c|}{ Índice DRIS } & \multirow[t]{2}{*}{ IBN } & \multirow{2}{*}{$\begin{array}{c}\text { Seqüência de } \\
\text { deficiência a excesso }\end{array}$} \\
\hline & & $\mathrm{N}$ & $\mathrm{P}$ & $\mathrm{K}$ & $\mathrm{Ca}$ & $\mathrm{Mg}$ & $\mathrm{S}$ & $\mathrm{B}$ & $\mathrm{Cu}$ & $\mathrm{Fe}$ & $\mathrm{Mn}$ & $\mathrm{Zn}$ & & \\
\hline 01 & 24 & 71 & 33 & 60 & 63 & 65 & -37 & 63 & 53 & 58 & 73 & 75 & 59 & $\mathrm{~S}>\mathrm{P}>\mathrm{Cu}>\mathrm{Fe}>\mathrm{K}>\mathrm{Ca}>\mathrm{B}>\mathrm{Mg}>\mathrm{N}>\mathrm{Mn}>\mathrm{Zn}$ \\
\hline 02 & 27 & 48 & 22 & -30 & -1 & -5 & -7 & 19 & 3 & -11 & 4 & -5 & 14 & $\mathrm{~K}>\mathrm{B}>\mathrm{Fe}>\mathrm{S}>\mathrm{Mg}>\mathrm{Zn}>\mathrm{Ca}>\mathrm{Cu}>\mathrm{Mn}>\mathrm{P}>\mathrm{N}$ \\
\hline 03 & 25 & 30 & 13 & -25 & 17 & 11 & -18 & 7 & -10 & 0 & -36 & 10 & 16 & $\mathrm{Mn}>\mathrm{K}>\mathrm{S}>\mathrm{Cu}>\mathrm{Fe}>\mathrm{B}>\mathrm{Zn}>\mathrm{Mg}>\mathrm{P}>\mathrm{Ca}>\mathrm{N}$ \\
\hline 04 & 24 & -8 & -19 & -9 & 2 & -4 & -12 & 0 & 76 & -6 & -6 & -12 & 14 & $\mathrm{P}>\mathrm{S}>\mathrm{Zn}>\mathrm{K}>\mathrm{N}>\mathrm{Fe}>\mathrm{Mn}>\mathrm{Mg}>\mathrm{B}>\mathrm{Ca}>\mathrm{Cu}$ \\
\hline 05 & 25 & 27 & -4 & -8 & -9 & 21 & -31 & 5 & -12 & 11 & 9 & -10 & 13 & $\mathrm{~S}>\mathrm{Cu}>\mathrm{Zn}>\mathrm{Ca}>\mathrm{K}>\mathrm{P}>\mathrm{B}>\mathrm{Mn}>\mathrm{Fe}>\mathrm{Mg}>\mathrm{N}$ \\
\hline 06 & 33 & -12 & -41 & -17 & -19 & -7 & 18 & 6 & -13 & 2 & 22 & 22 & 16 & $\mathrm{P}>\mathrm{K}>\mathrm{Cu}>\mathrm{N}>\mathrm{Mg}>\mathrm{Fe}>\mathrm{B}>\mathrm{S}>\mathrm{Ca}>\mathrm{Mn}>\mathrm{Zn}$ \\
\hline 07 & 24 & -54 & 1 & 1 & -22 & -21 & 37 & 20 & -32 & 14 & 31 & 26 & 24 & $\mathrm{~N}>\mathrm{Cu}>\mathrm{Ca}>\mathrm{Mg}>\mathrm{P}>\mathrm{K}>\mathrm{Fe}>\mathrm{B}>\mathrm{Zn}>\mathrm{Mn}>\mathrm{S}$ \\
\hline 08 & 25 & 24 & 1 & -10 & -1 & 25 & -26 & -8 & 9 & 8 & 11 & -33 & 14 & $\mathrm{Zn}>\mathrm{S}>\mathrm{K}>\mathrm{B}>\mathrm{Ca}>\mathrm{P}>\mathrm{Fe}>\mathrm{Cu}>\mathrm{Mn}>\mathrm{N}>\mathrm{Mg}$ \\
\hline 09 & 26 & 2 & -7 & -13 & -6 & 5 & 17 & -9 & 39 & -16 & -3 & -9 & 11 & $\mathrm{Fe}>\mathrm{K}>\mathrm{B}>\mathrm{Zn}>\mathrm{P}>\mathrm{Ca}>\mathrm{Mn}>\mathrm{N}>\mathrm{Mg}>\mathrm{S}>\mathrm{Cu}$ \\
\hline 10 & 26 & -21 & 5 & -9 & -28 & -16 & 22 & 11 & -38 & 20 & 27 & 28 & 20 & $\mathrm{Cu}>\mathrm{Ca}>\mathrm{N}>\mathrm{Mg}>\mathrm{K}>\mathrm{P}>\mathrm{B}>\mathrm{Fe}>\mathrm{S}>\mathrm{Mn}>\mathrm{Zn}$ \\
\hline 11 & 26 & 3 & -8 & -27 & -14 & -14 & 22 & 5 & -23 & 15 & 22 & 21 & 16 & $\mathrm{~K}>\mathrm{Cu}>\mathrm{Ca}>\mathrm{Mg}>\mathrm{P}>\mathrm{N}>\mathrm{B}>\mathrm{Fe}>\mathrm{Zn}>\mathrm{S}>\mathrm{Mn}$ \\
\hline 12 & 30 & -3 & -6 & -7 & 1 & 16 & 17 & -9 & -6 & -11 & -6 & 0 & 7 & $\mathrm{Fe}>\mathrm{B}>\mathrm{K}>\mathrm{P}>\mathrm{Cu}>\mathrm{N}>\mathrm{Zn}>\mathrm{Ca}>\mathrm{Mn}>\mathrm{Mg}>\mathrm{S}$ \\
\hline 13 & 36 & -8 & 0 & -1 & -7 & -26 & -18 & 4 & 34 & 13 & 7 & 2 & 11 & $\mathrm{MG}>\mathrm{S}>\mathrm{N}>\mathrm{Ca}>\mathrm{K}>\mathrm{P}>\mathrm{Zn}>\mathrm{B}>\mathrm{Mn}>\mathrm{Fe}>\mathrm{Cu}$ \\
\hline 14 & 30 & 8 & 15 & 14 & 13 & -3 & -8 & 11 & -12 & 0 & -21 & 16 & 11 & $\mathrm{Mn}>\mathrm{Zn}>\mathrm{Cu}>\mathrm{S}>\mathrm{Mg}>\mathrm{Fe}>\mathrm{N}>\mathrm{B}>\mathrm{Ca}>\mathrm{K}>\mathrm{P}$ \\
\hline 15 & 31 & -5 & -5 & -2 & 2 & -5 & -9 & 10 & -3 & -2 & -2 & 19 & 6 & $\mathrm{~S}>\mathrm{N}>\mathrm{P}>\mathrm{Mg}>\mathrm{Cu}>\mathrm{K}>\mathrm{Fe}>\mathrm{Mn}>\mathrm{Ca}>\mathrm{B}>\mathrm{Zn}$ \\
\hline 16 & 24 & -58 & 6 & -73 & -19 & -55 & -11 & 49 & 9 & 21 & 28 & -12 & 31 & $\mathrm{~K}>\mathrm{Mg}>\mathrm{Ca}>\mathrm{Zn}>\mathrm{S}>\mathrm{P}>\mathrm{Cu}>\mathrm{Fe}>\mathrm{Mn}>\mathrm{B}>\mathrm{N}$ \\
\hline 17 & 24 & -8 & 28 & -14 & -18 & -86 & -31 & 31 & 90 & 0 & 14 & -6 & 30 & $\mathrm{Mg}>\mathrm{S}>\mathrm{Ca}>\mathrm{K}>\mathrm{N}>\mathrm{Zn}>\mathrm{Fe}>\mathrm{Mn}>\mathrm{P}>\mathrm{B} .>\mathrm{Cu}$ \\
\hline 18 & 24 & -4 & 10 & -8 & 15 & 23 & -15 & 2 & -24 & 19 & 6 & -24 & 14 & $\mathrm{Cu}>\mathrm{Zn}>\mathrm{S}>\mathrm{K}>\mathrm{N}>\mathrm{B}>\mathrm{Mn}>\mathrm{P}>\mathrm{Ca} . \mathrm{Fe}>\mathrm{Mg}$ \\
\hline 19 & 26 & 27 & 19 & -87 & 0 & -17 & 17 & 17 & -15 & 15 & 16 & 9 & 22 & $\mathrm{~K}>\mathrm{Mg}>\mathrm{Cu}>\mathrm{Ca}>\mathrm{Zn}>\mathrm{Fe}>\mathrm{Mn}>\mathrm{S}>\mathrm{B}>\mathrm{P}>\mathrm{N}$ \\
\hline 20 & 36 & 8 & 16 & 5 & 28 & 17 & -7 & -9 & 4 & 0 & -5 & 0 & 9 & $\mathrm{Ca}>\mathrm{B}>\mathrm{S}>\mathrm{Mn}>\mathrm{Fe}>\mathrm{Zn}>\mathrm{Cu}>\mathrm{K}>\mathrm{N}>\mathrm{P}>\mathrm{Mg}$ \\
\hline
\end{tabular}


TABELA 3 - Produção, Índices DRIS, Índices de Balanço Nutricional (IBN) e Seqüência de deficiência a excesso nutricional para os vinhedos amostrados considerando limbo- $2^{\mathrm{a}}$ coleta (fruto entre ervilha e meia-baga).

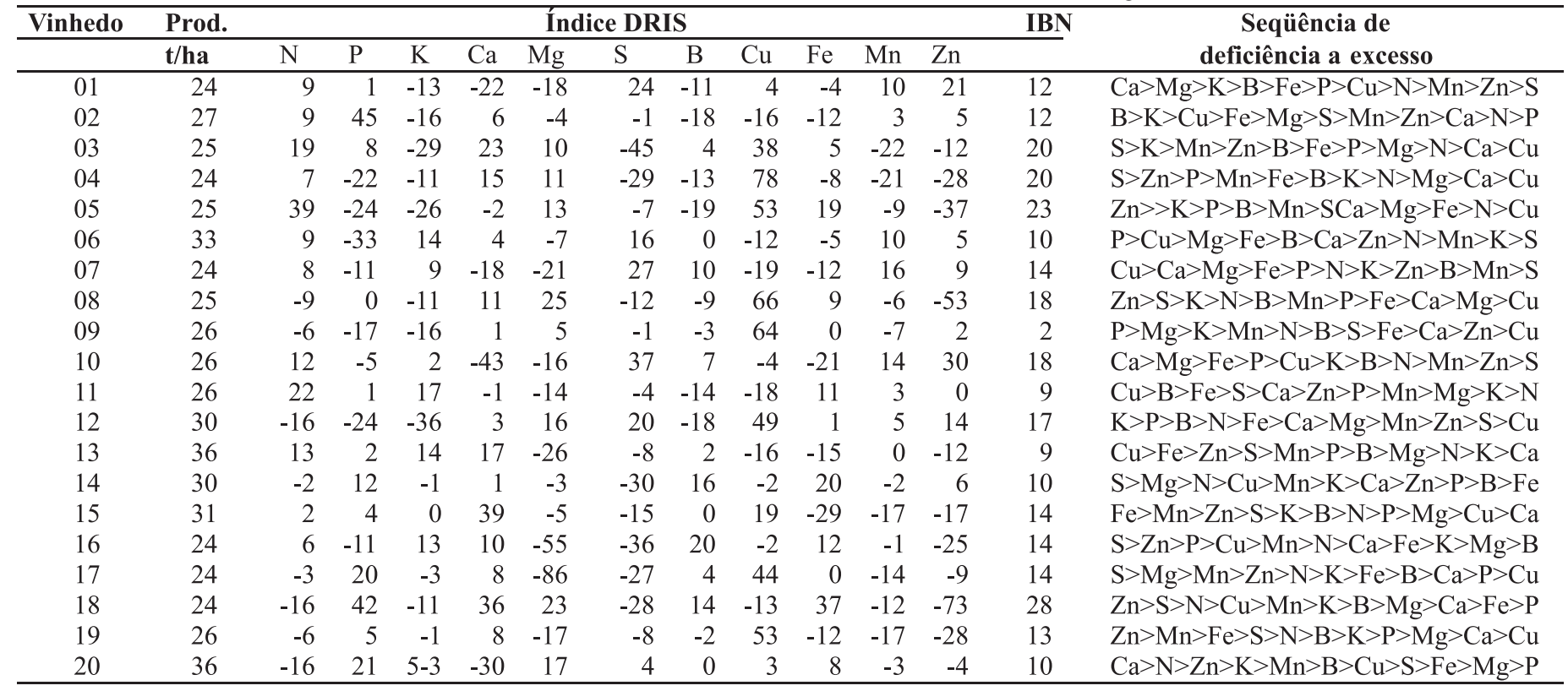

TABELA 4 - Produção, Índices DRIS, Índices de Balanço Nutricional (IBN) e Seqüência de deficiência a excesso nutricional para os vinhedos amostrados considerando limbo- $3^{\text {a }}$ coleta (início de amolecimento das bagas).

\begin{tabular}{|c|c|c|c|c|c|c|c|c|c|c|c|c|c|c|}
\hline \multirow[t]{2}{*}{ Vinhedo } & \multirow{2}{*}{$\begin{array}{l}\text { Prod. } \\
\text { t/ha }\end{array}$} & \multicolumn{11}{|c|}{ Índice DRIS } & \multirow[t]{2}{*}{ IBN } & \multirow{2}{*}{$\begin{array}{c}\text { Seqüência de } \\
\text { deficiência a excesso }\end{array}$} \\
\hline & & $\mathrm{N}$ & $\mathrm{P}$ & $\mathrm{K}$ & $\mathrm{Ca}$ & $\mathrm{Mg}$ & $\mathrm{S}$ & $\mathrm{B}$ & $\mathrm{Cu}$ & $\mathrm{Fe}$ & $\mathrm{Mn}$ & $\mathrm{Zn}$ & & \\
\hline 01 & 24 & -9 & -5 & -16 & -16 & -12 & 24 & 0 & 5 & 7 & 6 & 17 & 11 & $\mathrm{~K}>\mathrm{Ca}>\mathrm{Mg}>\mathrm{N}>\mathrm{P}>\mathrm{B}>\mathrm{Cu}>\mathrm{Mn}>\mathrm{Fe}>\mathrm{Zn}>\mathrm{S}$ \\
\hline 02 & 27 & -12 & 24 & 33 & -5 & 18 & -82 & 2 & 32 & -26 & 16 & 0 & 23 & $\mathrm{~S}>\mathrm{Fe}>\mathrm{N}>\mathrm{Ca}>\mathrm{Zn}>\mathrm{B}>\mathrm{Mn}>\mathrm{Mg}>\mathrm{P}>\mathrm{Cu}>\mathrm{K}$ \\
\hline 03 & 25 & -1 & 3 & -17 & 7 & -9 & -17 & 0 & 25 & 8 & 4 & -3 & 9 & $\mathrm{~K}>\mathrm{S}>\mathrm{Mg}>\mathrm{Zn}>\mathrm{N}>\mathrm{B}>\mathrm{P}>\mathrm{Mn}>\mathrm{Ca}>\mathrm{Fe}>\mathrm{Cu}$ \\
\hline 04 & 24 & -11 & -31 & -28 & 19 & -8 & 4 & -2 & 53 & 3 & -8 & 8 & 16 & $\mathrm{P}>\mathrm{K}>\mathrm{N}>\mathrm{Mg}>\mathrm{Mn}>\mathrm{B}>\mathrm{Fe}>\mathrm{S}>\mathrm{Zn}>\mathrm{Ca}>\mathrm{Cu}$ \\
\hline 05 & 25 & -3 & -10 & -25 & 0 & -1 & 3 & 0 & 41 & 8 & -5 & -9 & 10 & $\mathrm{~K}>\mathrm{P}>\mathrm{Zn}>\mathrm{Mn}>\mathrm{N}>\mathrm{Mg}>\mathrm{Ca}>\mathrm{B}>\mathrm{S}>\mathrm{Fe}>\mathrm{Cu}$ \\
\hline 06 & 33 & -18 & -51 & -13 & 16 & -1 & 28 & -11 & 21 & 4 & 8 & 17 & 17 & $\mathrm{P}>\mathrm{N}>\mathrm{K}>\mathrm{B}>\mathrm{Mg}>\mathrm{Fe}>\mathrm{Mn}>\mathrm{Ca}>\mathrm{Zn}>\mathrm{Cu}>\mathrm{S}$ \\
\hline 07 & 24 & -8 & -8 & -8 & -7 & -33 & 22 & 6 & -11 & 12 & 13 & 22 & 14 & $\mathrm{Mg}>\mathrm{Cu}>\mathrm{N}>\mathrm{PK}>\mathrm{Ca}>\mathrm{B}>\mathrm{Fe}>\mathrm{Mn}>\mathrm{S}>\mathrm{Zn}$ \\
\hline 08 & 25 & -4 & -11 & -26 & 3 & 1 & -5 & -1 & 46 & 9 & 8 & -20 & 12 & $\mathrm{~K}>\mathrm{Zn}>\mathrm{P}>\mathrm{S}>\mathrm{B}>\mathrm{B}>\mathrm{Mg}>\mathrm{Ca}>\mathrm{Mn}>\mathrm{Fe}>\mathrm{Cu}$ \\
\hline 09 & 26 & -7 & -15 & -25 & -5 & -13 & 3 & -2 & 41 & 6 & 10 & 3 & 12 & $\mathrm{~K}>\mathrm{P}>\mathrm{Mg}>\mathrm{Ca}>\mathrm{N}>\mathrm{B}>\mathrm{S}>\mathrm{Zn}>\mathrm{Fe}>\mathrm{Mn}>\mathrm{Cu}$ \\
\hline 10 & 26 & 1 & 1 & -14 & -12 & 24 & 12 & 2 & -2 & 6 & 14 & 25 & 11 & $\mathrm{Mg}>\mathrm{K}>\mathrm{Ca}>\mathrm{N}>\mathrm{Cu}>\mathrm{P}>\mathrm{B}>\mathrm{Fe}>\mathrm{S}>\mathrm{Mn}>\mathrm{Zn}$ \\
\hline 11 & 26 & -2 & -5 & -8 & 3 & -11 & 11 & -10 & -8 & 6 & 8 & -4 & 6 & $\mathrm{Mg}>\mathrm{K}>\mathrm{Cu}>\mathrm{P}>\mathrm{B}>\mathrm{N}>\mathrm{Ca}>\mathrm{Zn}>\mathrm{Fe}>\mathrm{Mn}>\mathrm{S}$ \\
\hline 12 & 30 & -3 & -10 & -29 & -10 & -4 & 21 & 13 & 37 & 4 & -12 & 14 & 14 & $\mathrm{~K}>\mathrm{Mn}>\mathrm{P}>\mathrm{Ca}>\mathrm{B}>\mathrm{Mg}>\mathrm{N}>\mathrm{Fe}>\mathrm{Zn}>\mathrm{S}>\mathrm{Cu}$ \\
\hline 13 & 36 & 1 & -11 & -9 & 7 & -14 & 14 & 6 & -7 & 18 & 7 & 4 & 11 & $\mathrm{Cu}>\mathrm{Mg}>\mathrm{P}>\mathrm{K}>\mathrm{Zn}>\mathrm{N}>\mathrm{Ca}>\mathrm{Mn}>\mathrm{B}>\mathrm{S}>\mathrm{Fe}$ \\
\hline 14 & 30 & -19 & 12 & -13 & 6 & 20 & -8 & 13 & 11 & 4 & 7 & -6 & 9 & $\mathrm{Mg}>\mathrm{K}>\mathrm{S}>\mathrm{Zn}>\mathrm{N}>\mathrm{Fe}>\mathrm{Ca}>\mathrm{B}>\mathrm{Mn}>\mathrm{Cu}>\mathrm{P}$ \\
\hline 15 & 31 & 3 & -1 & -20 & 7 & -12 & 8 & 20 & 11 & 6 & -5 & 10 & 10 & $\mathrm{~K}>\mathrm{N}>\mathrm{Mg}>\mathrm{Mn}>\mathrm{P}>\mathrm{Fe}>\mathrm{Ca}>\mathrm{S}>\mathrm{Zn}>\mathrm{Cu}>\mathrm{B}$ \\
\hline 16 & 24 & -14 & -9 & 0 & -5 & -11 & 17 & -7 & 0 & 15 & -13 & -16 & 10 & $\mathrm{Zn}>\mathrm{Mn}>\mathrm{Mg}>\mathrm{P}>\mathrm{Ca}>\mathrm{K}>\mathrm{Cu}>\mathrm{N}>\mathrm{Fe}>\mathrm{S}>\mathrm{B}$ \\
\hline 17 & 24 & -8 & 36 & -16 & 5 & -34 & 17 & 21 & 33 & -11 & -14 & -5 & 17 & $\mathrm{Mg}>\mathrm{K}>\mathrm{N}>\mathrm{Mn}>\mathrm{B}>\mathrm{Zn}>\mathrm{Fe}>\mathrm{Ca}>\mathrm{S}>\mathrm{Cu}>\mathrm{P}$ \\
\hline 18 & 24 & -22 & 14 & 24 & 21 & 33 & -72 & 7 & -5 & -1 & -6 & -8 & 21 & $\mathrm{~S}>\mathrm{Fe}>\mathrm{N}>\mathrm{Zn}>\mathrm{Mn}>\mathrm{Cu}>\mathrm{P}>\mathrm{Ca}>\mathrm{B}>\mathrm{K}>\mathrm{Mg}$ \\
\hline 19 & 26 & -2 & 2 & -18 & 0 & -13 & 11 & 20 & 42 & 4 & -5 & -8 & 12 & $\mathrm{~N}>\mathrm{K}>\mathrm{Mg}>\mathrm{Zn}>\mathrm{Mn}>\mathrm{Ca}>\mathrm{P}>\mathrm{Fe}>\mathrm{B}>\mathrm{S}>\mathrm{Cu}$ \\
\hline 20 & 36 & -16 & 18 & 37 & -28 & 36 & -43 & 9 & -25 & -13 & 10 & 2 & 20 & $\mathrm{~S}>\mathrm{Ca}>\mathrm{Cu}>\mathrm{Fe}>\mathrm{N}>\mathrm{Zn}>\mathrm{B}>\mathrm{Mn}>\mathrm{P}>\mathrm{Mg}>\mathrm{K}$ \\
\hline
\end{tabular}

TABELA 5 - Produção, Índices DRIS, Índices de Balanço Nutricional (IBN) e Seqüência de deficiência a excesso nutricional para os vinhedos amostrados considerando Pecíolo- $1^{\text {a }}$ coleta (florescimento).

\begin{tabular}{|c|c|c|c|c|c|c|c|c|c|c|c|c|c|c|}
\hline \multirow[t]{2}{*}{ Vinhedo } & \multirow{2}{*}{$\begin{array}{l}\text { Prod } \\
\text { t/ha }\end{array}$} & \multicolumn{11}{|c|}{ Índice DRIS } & \multirow[t]{2}{*}{ IBN } & \multirow{2}{*}{$\begin{array}{c}\text { Seqüência de } \\
\text { deficiência a excesso }\end{array}$} \\
\hline & & $\mathrm{N}$ & $\mathrm{P}$ & $\mathrm{K}$ & $\mathrm{Ca}$ & $\mathrm{Mg}$ & $\mathrm{S}$ & $\mathrm{B}$ & $\mathrm{Cu}$ & $\mathrm{Fe}$ & $\mathrm{Mn}$ & $\mathrm{Zn}$ & & \\
\hline 01 & 24 & -11 & 11 & 4 & -15 & -18 & 16 & -12 & -6 & -2 & 12 & 13 & 10 & $\mathrm{Ca}>\mathrm{B}>\mathrm{N}>\mathrm{Mg}>\mathrm{Cu}>\mathrm{Fe}>\mathrm{K}>\mathrm{P}>\mathrm{Mn}>\mathrm{Zn}>\mathrm{S}$ \\
\hline 02 & 27 & 10 & 16 & -1 & -3 & -1 & 2 & -21 & 19 & -6 & -2 & -14 & 9 & $\mathrm{~B}>\mathrm{Zn}>\mathrm{Fe}>\mathrm{Ca}>\mathrm{Mn}>\mathrm{K}>\mathrm{Mg}>\mathrm{S}>\mathrm{N}>\mathrm{P}>\mathrm{Cu}$ \\
\hline 03 & 25 & 19 & 5 & 6 & 12 & 4 & 22 & -9 & -4 & 7 & -36 & -27 & 14 & $\mathrm{Mn}>\mathrm{Zn}>\mathrm{B}>\mathrm{Cu}>\mathrm{Mg}>\mathrm{P}>\mathrm{K}>\mathrm{Fe}>\mathrm{Ca}>\mathrm{N}>\mathrm{S}$ \\
\hline 04 & 24 & -7 & -5 & -14 & 11 & 14 & -32 & 0 & 100 & 7 & -26 & -33 & 23 & $\mathrm{Zn}>\mathrm{S}>\mathrm{Mn}>\mathrm{K}>\mathrm{N}>\mathrm{Fe}>\mathrm{P}>\mathrm{B}>\mathrm{Ca}>\mathrm{Mg}>\mathrm{Cu}$ \\
\hline 05 & 25 & 6 & -2 & 5 & -11 & 32 & -16 & -16 & 19 & -7 & -3 & -7 & 11 & $\mathrm{~S}>\mathrm{B}>\mathrm{Ca}>\mathrm{Fe}>\mathrm{Zn}>\mathrm{Mn}>\mathrm{P}>\mathrm{K}>\mathrm{N}>\mathrm{Cu}>\mathrm{Mg}$ \\
\hline 06 & 33 & -20 & -37 & 4 & 19 & 0 & 8 & 2 & 28 & -10 & 0 & 8 & 12 & $\mathrm{P}>\mathrm{N}>\mathrm{Fe}>\mathrm{Mg}>\mathrm{Mn}>\mathrm{B}>\mathrm{K}>\mathrm{S}>\mathrm{Zn}>\mathrm{Ca}>\mathrm{Cu}$ \\
\hline 07 & 24 & -11 & -6 & -2 & 0 & -11 & 11 & 7 & -19 & 14 & 2 & 15 & 9 & $\mathrm{Cu}>\mathrm{N}>\mathrm{Mg}>\mathrm{P}>\mathrm{K}>\mathrm{Ca}>\mathrm{Mn}>\mathrm{B}>\mathrm{S}>\mathrm{Fe}>\mathrm{Zn}$ \\
\hline 08 & 25 & 24 & -6 & -17 & -41 & 13 & 3 & 11 & 18 & -9 & 16 & -12 & 14 & $\mathrm{Ca}>\mathrm{K}>\mathrm{Fe}>\mathrm{P}>\mathrm{Zn}>\mathrm{B}>\mathrm{S}>\mathrm{Mg}>\mathrm{Mn}>\mathrm{Cu}>\mathrm{N}$ \\
\hline 09 & 26 & 5 & -4 & -27 & -26 & -4 & 23 & 2 & 28 & 0 & -1 & 4 & 11 & $\mathrm{~K}>\mathrm{Ca}>\mathrm{P}>\mathrm{Mg}>\mathrm{Mn}>\mathrm{Fe}>\mathrm{B}>\mathrm{Zn}>\mathrm{N}>\mathrm{S}>\mathrm{Cu}$ \\
\hline 10 & 26 & -25 & 16 & -5 & -4 & -4 & 12 & 13 & -31 & 4 & 9 & 16 & 13 & $\mathrm{Cu}>\mathrm{N}>\mathrm{K}>\mathrm{Ca}>\mathrm{Mg}>\mathrm{Fe}>\mathrm{Mn}>\mathrm{S}>\mathrm{B}>\mathrm{P}>\mathrm{Zn}$ \\
\hline 11 & 26 & -34 & 6 & 1 & 14 & 6 & -9 & -4 & -20 & 16 & 3 & 21 & 12 & $\mathrm{~N}>\mathrm{Cu}>\mathrm{S}>\mathrm{B}>\mathrm{K}>\mathrm{Mn}>\mathrm{P}>\mathrm{Mg}>\mathrm{Ca}>\mathrm{Fe}>\mathrm{Zn}$ \\
\hline 12 & 30 & -4 & 0 & -41 & -13 & 24 & 25 & -2 & -4 & -3 & 13 & 4 & 12 & $\mathrm{~K}>\mathrm{Ca}>\mathrm{N}>\mathrm{Cu}>\mathrm{Fe}>\mathrm{B}>\mathrm{P}>\mathrm{Zn}>\mathrm{Mn}>\mathrm{Mg}>\mathrm{S}$ \\
\hline 13 & 36 & -11 & 10 & 9 & 5 & -12 & -41 & 15 & -8 & 23 & 11 & -1 & 13 & $\mathrm{~S}>\mathrm{Mg}>\mathrm{N}>\mathrm{Cu}>\mathrm{Zn}>\mathrm{Ca}>\mathrm{K}>\mathrm{P}>\mathrm{Mn}>\mathrm{B}>\mathrm{Fe}$ \\
\hline 14 & 30 & 18 & 2 & 7 & 9 & -21 & 3 & 3 & -13 & -2 & -5 & -2 & 8 & $\mathrm{Mg}>\mathrm{Cu}>\mathrm{Mn}>\mathrm{Fe}>\mathrm{Zn}>\mathrm{P}>\mathrm{S}>\mathrm{B}>\mathrm{K}>\mathrm{Ca}>\mathrm{N}$ \\
\hline 15 & 31 & -11 & -3 & 15 & 17 & 7 & -20 & 19 & -32 & 14 & 9 & 1 & 13 & $\mathrm{Cu}>\mathrm{S}>\mathrm{N}>\mathrm{Mn}>\mathrm{P}>\mathrm{Zn}>\mathrm{Mg}>\mathrm{Fe}>\mathrm{K}>\mathrm{Ca}>\mathrm{B}$ \\
\hline 16 & 24 & 15 & 16 & -24 & -8 & -30 & -9 & 61 & -19 & -40 & 18 & 20 & 24 & $\mathrm{Fe}>\mathrm{Mg}>\mathrm{K}>\mathrm{Cu}>\mathrm{S}>\mathrm{Ca}>\mathrm{N}>\mathrm{P}>\mathrm{Mn}>\mathrm{Zn}>\mathrm{B}$ \\
\hline 17 & 24 & -18 & 19 & -1 & -25 & -76 & 10 & 34 & 62 & 10 & -3 & -11 & 24 & $\mathrm{Mg}>\mathrm{Ca}>\mathrm{N}>\mathrm{Zn}>\mathrm{Mn}>\mathrm{K}>\mathrm{S}>\mathrm{Fe}>\mathrm{P}>\mathrm{B}>\mathrm{Cu}$ \\
\hline 18 & 24 & 4 & 6 & 1 & -5 & 10 & 1 & -16 & -2 & 3 & -5 & -8 & 6 & $\mathrm{~B}>\mathrm{Zn}>\mathrm{Ca}>\mathrm{Mn}>\mathrm{Cu}>\mathrm{K}>\mathrm{S}>\mathrm{N}>\mathrm{P}>\mathrm{Mg}>\mathrm{Fe}$ \\
\hline 19 & 26 & 1 & 20 & -15 & -29 & 2 & -4 & 16 & -15 & 15 & -5 & 5 & 12 & $\mathrm{Ca}>\mathrm{K}>\mathrm{Cu}>\mathrm{S}>\mathrm{N}>\mathrm{Mg}>\mathrm{Mn}>\mathrm{Zn}>\mathrm{Fe}>\mathrm{B}>\mathrm{P}$ \\
\hline 20 & 36 & 7 & 12 & 8 & -24 & 11 & 2 & 11 & 6 & 1 & -10 & 0 & 8 & $\mathrm{Ca}>\mathrm{B}>\mathrm{Mn}>\mathrm{Zn}>\mathrm{Fe}>\mathrm{S}>\mathrm{Cu}>\mathrm{N}>\mathrm{K}>\mathrm{Mg}>\mathrm{P}$ \\
\hline
\end{tabular}


TABELA 6-Produção, Índices DRIS, Índices de Balanço Nutricional (IBN) e Sequiência de deficiência a excesso nutricional para os vinhedos amostrados considerando Pecíolo- $2^{\mathrm{a}}$ coleta (fruto entre ervilha e meia-baga).

\begin{tabular}{|c|c|c|c|c|c|c|c|c|c|c|c|c|c|c|}
\hline \multirow[t]{2}{*}{ Vinhedo } & \multirow{2}{*}{$\begin{array}{l}\text { Prod } \\
\text { t/ha }\end{array}$} & \multicolumn{11}{|c|}{ Índice DRIS } & \multirow[t]{2}{*}{ IBN } & \multirow{2}{*}{$\begin{array}{c}\text { Seqüência de } \\
\text { deficiência a excesso }\end{array}$} \\
\hline & & $\mathrm{N}$ & $\mathrm{P}$ & $\mathrm{K}$ & $\mathrm{Ca}$ & $\mathrm{Mg}$ & $\mathrm{S}$ & $\mathrm{B}$ & $\mathrm{Cu}$ & $\mathrm{Fe}$ & $\mathrm{Mn}$ & $\mathrm{Zn}$ & & \\
\hline 01 & 24 & 55 & 4 & -7 & -12 & -13 & -22 & -8 & -13 & -9 & 6 & 20 & 15 & $\mathrm{~S}>\mathrm{Mg}>\mathrm{Cu}>\mathrm{Ca}>\mathrm{Fe}>\mathrm{B}>\mathrm{K}>\mathrm{P}>\mathrm{Mn}>\mathrm{Zn}>\mathrm{N}$ \\
\hline 02 & 27 & 73 & 26 & -16 & 0 & 1 & -19 & -21 & -20 & -8 & 0 & -17 & 18 & $\mathrm{~B}>\mathrm{Cu}>\mathrm{S}>\mathrm{Zn}>\mathrm{K}>\mathrm{Fe}>\mathrm{Ca}>\mathrm{Mn}>\mathrm{Mg}>\mathrm{P}>\mathrm{N}$ \\
\hline 03 & 25 & 155 & 5 & -10 & 4 & 3 & -106 & -12 & -14 & 2 & -10 & -45 & 33 & $\mathrm{~S}>\mathrm{Zn}>\mathrm{B}>\mathrm{K}>\mathrm{Mn}>\mathrm{Fe}>\mathrm{Mg}>\mathrm{Ca}>\mathrm{P}>\mathrm{Cu}>\mathrm{N}$ \\
\hline 04 & 24 & 16 & -21 & -3 & 14 & 12 & -9 & -10 & 57 & 4 & -40 & -26 & 19 & $\mathrm{Mn}>\mathrm{Zn}>\mathrm{P}>\mathrm{B}>\mathrm{S}>\mathrm{K}>\mathrm{Fe}>\mathrm{Mg}>\mathrm{Ca}>\mathrm{N}>\mathrm{Cu}$ \\
\hline 05 & 25 & 106 & -14 & -20 & -11 & 12 & -55 & -26 & 30 & 7 & -4 & -25 & 28 & $\mathrm{~S}>\mathrm{B}>\mathrm{Zn}>\mathrm{K}>\mathrm{P}>\mathrm{Ca}>\mathrm{Mn}>\mathrm{Fe}>\mathrm{Mg}>\mathrm{Cu}>\mathrm{N}$ \\
\hline 06 & 33 & 21 & -33 & 15 & 2 & -13 & 28 & -5 & -11 & -7 & -4 & 6 & 13 & $\mathrm{P}>\mathrm{Mg}>\mathrm{Cu}>\mathrm{Fe}>\mathrm{B}>\mathrm{Mn}>\mathrm{Ca}>\mathrm{Zn}>\mathrm{K}>\mathrm{N}>\mathrm{S}$ \\
\hline 07 & 24 & 1 & -6 & 10 & -10 & -48 & 19 & 8 & -14 & 8 & 14 & 16 & 14 & $\mathrm{Mg}>\mathrm{Cu}>\mathrm{CA}>\mathrm{P}>\mathrm{N}>\mathrm{B}>\mathrm{Fe}>\mathrm{K}>\mathrm{Mn}>\mathrm{Zn}>\mathrm{S}$ \\
\hline 08 & 25 & 17 & -9 & -14 & 2 & 16 & -16 & -20 & 45 & -5 & 16 & -30 & 17 & $\mathrm{Zn}>\mathrm{B}>\mathrm{S}>\mathrm{K}>\mathrm{P}>\mathrm{Fe}>\mathrm{Ca}>\mathrm{Mg}>\mathrm{Mn}>\mathrm{N} . \mathrm{Cu}$ \\
\hline 09 & 26 & 0 & -2 & -8 & 4 & 9 & -29 & 0 & 50 & -2 & -19 & -3 & 11 & $\mathrm{~S}>\mathrm{Mn}>\mathrm{K}>\mathrm{Zn}>\mathrm{P}>\mathrm{Fe}>\mathrm{N}>\mathrm{B}>\mathrm{Ca}>\mathrm{Mg}>\mathrm{Cu}$ \\
\hline 10 & 26 & 10 & 0 & 10 & -39 & -42 & 17 & 7 & -11 & -4 & 18 & 34 & 17 & $\mathrm{Mg}>\mathrm{Ca}>\mathrm{Cu}>\mathrm{Fe}>\mathrm{P}>\mathrm{B}>\mathrm{N}>\mathrm{K}>\mathrm{S}>\mathrm{Mn}>\mathrm{Zn}$ \\
\hline 11 & 26 & 6 & 2 & 11 & -3 & 0 & -3 & -13 & -20 & 4 & 6 & 10 & 7 & $\mathrm{Cu}>\mathrm{B}>\mathrm{Ca}>\mathrm{S}>\mathrm{Mg}>\mathrm{P}>\mathrm{Fe}>\mathrm{N}>\mathrm{Mn}>\mathrm{Zn}>\mathrm{K}$ \\
\hline 12 & 30 & -2 & -7 & -34 & -1 & 15 & 0 & -13 & 34 & -2 & 7 & 2 & 11 & $\mathrm{~K}>\mathrm{B}>\mathrm{P}>\mathrm{N}>\mathrm{Fe}>\mathrm{Ca}>\mathrm{S}>\mathrm{Zn}>\mathrm{Mn}>\mathrm{Mg}>\mathrm{Cu}$ \\
\hline 13 & 36 & 1 & 4 & 19 & 10 & -9 & -10 & 14 & -23 & -11 & 1 & 4 & 10 & $\mathrm{Cu}>\mathrm{Fe}>\mathrm{S}>\mathrm{Mg}>\mathrm{N}>\mathrm{Mn}>\mathrm{P}>\mathrm{ZN}>\mathrm{Ca}>\mathrm{B}>\mathrm{K}$ \\
\hline 14 & 30 & -19 & 3 & -11 & 16 & -10 & -8 & 3 & 4 & 16 & 4 & 2 & 9 & $\mathrm{~N}>\mathrm{K}>\mathrm{Mg}>\mathrm{S}>\mathrm{Zn}>\mathrm{P}>\mathrm{B}>\mathrm{Cu}>\mathrm{Mn}>\mathrm{Ca}>\mathrm{Fe}$ \\
\hline 15 & 31 & 5 & -6 & 10 & 25 & 1 & -13 & 7 & 8 & 3 & -27 & -13 & 11 & $\mathrm{Mn}>\mathrm{S}>\mathrm{Zn}>\mathrm{P}>\mathrm{Mg}>\mathrm{Fe}>\mathrm{N}>\mathrm{B}>\mathrm{Cu}>\mathrm{K}>\mathrm{Ca}$ \\
\hline 16 & 24 & 60 & 19 & 25 & 28 & 32 & -124 & 35 & -15 & 29 & 12 & -1 & 35 & $\mathrm{~S}>\mathrm{Cu}>\mathrm{Zn}>\mathrm{Mn}>\mathrm{P}>\mathrm{K}>\mathrm{Ca}>\mathrm{Fe}>\mathrm{Mg}>\mathrm{B}>\mathrm{N}$ \\
\hline 17 & 24 & 19 & 29 & 1 & 30 & -43 & -70 & 7 & 42 & 17 & -13 & -17 & 26 & $\mathrm{~S}>\mathrm{Mg}>\mathrm{Zn}>\mathrm{Mn}>\mathrm{K}>\mathrm{B}>\mathrm{Fe}>\mathrm{N}>\mathrm{P}>\mathrm{Ca}>\mathrm{Cu}$ \\
\hline 18 & 24 & -1 & 23 & -9 & 3 & 19 & -28 & 1 & 9 & 19 & 3 & -39 & 14 & $\mathrm{Zn}>\mathrm{S}>\mathrm{K}>\mathrm{N}>\mathrm{B}>\mathrm{Ca}>\mathrm{Mn}>\mathrm{Cu}>\mathrm{Mg}>\mathrm{Fe}>\mathrm{P}$ \\
\hline 19 & 26 & -1 & 8 & 1 & 15 & -15 & -14 & -11 & 48 & 6 & -18 & -20 & 1 & $\mathrm{Zn}>\mathrm{Mn}>\mathrm{Mg}>\mathrm{S}>\mathrm{B}>\mathrm{N}>\mathrm{K}>\mathrm{Fe}>\mathrm{P}>\mathrm{Ca}>\mathrm{Cu}$ \\
\hline 20 & 36 & -11 & 20 & 0 & -34 & 18 & -8 & 3 & 7 & 11 & 0 & -7 & 11 & $\mathrm{Ca}>\mathrm{N}>\mathrm{S}>\mathrm{Zn}>\mathrm{K}>\mathrm{Mn}>\mathrm{B}>\mathrm{Cu}>\mathrm{Fe}>\mathrm{Mg}>\mathrm{P}$ \\
\hline
\end{tabular}

TABELA 7 - Produção, Índices DRIS, Índices de Balanço Nutricional (IBN) e Seqüência de deficiência a excesso nutricional para os vinhedos amostrados considerando Pecíolo- $3^{\text {a }}$ coleta (início de amolecimento das bagas).

\begin{tabular}{|c|c|c|c|c|c|c|c|c|c|c|c|c|c|c|}
\hline \multirow[t]{2}{*}{ Vinhedo } & \multirow{2}{*}{$\begin{array}{l}\text { Prod } \\
\text { t/ha }\end{array}$} & \multicolumn{11}{|c|}{ Índice DRIS } & \multirow[t]{2}{*}{ IBN } & \multirow{2}{*}{$\begin{array}{c}\text { Seqüência de } \\
\text { deficiência a excesso }\end{array}$} \\
\hline & & $\mathrm{N}$ & $\mathrm{P}$ & $\mathrm{K}$ & $\mathrm{Ca}$ & $\mathrm{Mg}$ & $\mathrm{S}$ & $\mathrm{B}$ & $\mathrm{Cu}$ & $\mathrm{Fe}$ & $\mathrm{Mn}$ & $\mathrm{Zn}$ & & \\
\hline 01 & 24 & -10 & 5 & 24 & -29 & -7 & -4 & -2 & 0 & -5 & 8 & -19 & 10 & $\mathrm{Ca}>\mathrm{N}>\mathrm{Mg}>\mathrm{Fe}>\mathrm{S}>\mathrm{B}>\mathrm{Cu}>\mathrm{P}>\mathrm{Mn}>\mathrm{Zn}>\mathrm{K}$ \\
\hline 02 & 27 & -4 & 18 & -73 & -15 & -82 & 65 & -27 & 73 & 14 & -2 & 33 & 37 & $\mathrm{Mg}>\mathrm{K}>\mathrm{B}>\mathrm{Ca}>\mathrm{N}>\mathrm{Mn}>\mathrm{Fe}>\mathrm{P}>\mathrm{Zn}>\mathrm{S}>\mathrm{Cu}$ \\
\hline 03 & 25 & 60 & 41 & 62 & 30 & 23 & -99 & 62 & 79 & 48 & 50 & 44 & 54 & $\mathrm{~S}>\mathrm{Mg}>\mathrm{Ca}>\mathrm{P}>\mathrm{Zn}>\mathrm{Fe}>\mathrm{Mn}>\mathrm{N}>\mathrm{K}>\mathrm{B}>\mathrm{Cu}$ \\
\hline 04 & 24 & -10 & -25 & -23 & 6 & 14 & 20 & 1 & 46 & -5 & -18 & -6 & 16 & $\mathrm{P}>\mathrm{K}>\mathrm{Mn}>\mathrm{N}>\mathrm{Zn}>\mathrm{Fe}>\mathrm{B}>\mathrm{Ca}>\mathrm{Mg}>\mathrm{S}>\mathrm{Cu}$ \\
\hline 05 & 25 & 6 & -8 & 12 & -29 & 24 & -51 & -8 & 49 & -1 & -3 & 10 & 18 & $\mathrm{~S}>\mathrm{Ca}>\mathrm{P}>\mathrm{B}>\mathrm{Mn}>\mathrm{Fe}>\mathrm{N}>\mathrm{Zn}>\mathrm{K}>\mathrm{Mg}>\mathrm{Cu}$ \\
\hline 06 & 33 & -14 & -45 & 2 & -4 & 1 & 28 & 1 & 18 & -5 & 7 & 11 & 2 & $\mathrm{P}>\mathrm{N}>\mathrm{Fe}>\mathrm{Ca}>\mathrm{Mg}>\mathrm{B}>\mathrm{K}>\mathrm{Mn}>\mathrm{Zn}>\mathrm{Cu}>\mathrm{S}$ \\
\hline 07 & 24 & -20 & -15 & -5 & -13 & 31 & 18 & 11 & -9 & -7 & 5 & 4 & 13 & $\mathrm{~N}>\mathrm{P}>\mathrm{Ca}>\mathrm{Cu}>\mathrm{Fe}>\mathrm{K}>\mathrm{Zn}>\mathrm{Mn}>\mathrm{B}>\mathrm{S}>\mathrm{Mg}$ \\
\hline 08 & 25 & 0 & -7 & 9 & -17 & 29 & -83 & -10 & 65 & 3 & 6 & 4 & 2 & $\mathrm{~S}>\mathrm{Ca}>\mathrm{B}>\mathrm{P}>\mathrm{N}>\mathrm{Fe}>\mathrm{Zn}>\mathrm{Mn}>\mathrm{K}>\mathrm{Mg}>\mathrm{Cu}$ \\
\hline 09 & 26 & -6 & -4 & 21 & -12 & -2 & -63 & 11 & 52 & -6 & 2 & 7 & 17 & $\mathrm{~S}>\mathrm{Ca}>\mathrm{N}>\mathrm{Fe}>\mathrm{P}>\mathrm{Mg}>\mathrm{Mn}>\mathrm{Zn}>\mathrm{B}>\mathrm{K}>\mathrm{Cu}$ \\
\hline 10 & 26 & -14 & -3 & -4 & -17 & -2 & 31 & 3 & -10 & -5 & 7 & 12 & 10 & $\mathrm{~K}>\mathrm{N}>\mathrm{Cu}>\mathrm{Fe}>\mathrm{K}>\mathrm{P}>\mathrm{Mg}>\mathrm{B}>\mathrm{Mn}>\mathrm{Zn}>\mathrm{S}$ \\
\hline 11 & 26 & -10 & 0 & 3 & -4 & 9 & 6 & 10 & -26 & -2 & 9 & 3 & 7 & $\mathrm{Cu}>\mathrm{N}>\mathrm{Ca}>\mathrm{Fe}>\mathrm{P}>\mathrm{K}>\mathrm{Zn}>\mathrm{S}>\mathrm{Mg}>\mathrm{Mn}>\mathrm{B}$ \\
\hline 12 & 30 & -6 & -2 & 2 & -24 & 27 & -23 & -15 & 40 & -8 & 3 & 7 & 14 & $\mathrm{Ca}>\mathrm{S}>\mathrm{B}>\mathrm{Fe}>\mathrm{N}>\mathrm{P}>\mathrm{K}>\mathrm{Mn}>\mathrm{Zn}>\mathrm{Mg}>\mathrm{Cu}$ \\
\hline 13 & 36 & -12 & -14 & 11 & -4 & -1 & 8 & 22 & -23 & 7 & 7 & 0 & 10 & $\mathrm{Cu}>\mathrm{P}>\mathrm{N}>\mathrm{Ca}>\mathrm{Mg}>\mathrm{Zn}>\mathrm{Fe}>\mathrm{Mn}>\mathrm{S}>\mathrm{K}>\mathrm{B}$ \\
\hline 14 & 30 & 5 & 20 & -68 & 24 & -28 & 24 & 2 & -1 & 29 & 0 & -7 & 19 & $\mathrm{~K}>\mathrm{Mg}>\mathrm{Zn}>\mathrm{Cu}>\mathrm{Mn}>\mathrm{B}>\mathrm{N}>\mathrm{P}>\mathrm{Ca}>\mathrm{S}>\mathrm{Fe}$ \\
\hline 15 & 31 & -17 & -15 & 12 & 10 & -9 & 9 & 17 & 6 & -6 & -7 & 0 & 10 & $\mathrm{~N}>\mathrm{P}>\mathrm{Mg}>\mathrm{Mn}>\mathrm{Fe}>\mathrm{Zn}>\mathrm{Cu}>\mathrm{S}>\mathrm{Ca}>\mathrm{K}>\mathrm{B}$ \\
\hline 16 & 24 & 1 & -4 & 39 & -61 & -26 & 6 & 36 & 13 & 3 & 6 & -12 & 19 & $\mathrm{CA}>\mathrm{Mg}>\mathrm{Zn}>\mathrm{P}>\mathrm{N}>\mathrm{Fe}>\mathrm{S}>\mathrm{Mn}>\mathrm{Cu}>\mathrm{B}>\mathrm{K}$ \\
\hline 17 & 24 & -10 & 17 & 17 & -12 & -47 & 43 & 9 & 36 & -28 & -5 & -21 & 22 & $\mathrm{Mg}>\mathrm{Fe}>\mathrm{Zn}>\mathrm{Ca}>\mathrm{N}>\mathrm{Mn}>\mathrm{B}>\mathrm{P}>\mathrm{K}>\mathrm{Cu}>\mathrm{S}$ \\
\hline 18 & 24 & 15 & 12 & -58 & -19 & -37 & 47 & -6 & 8 & 27 & -3 & 13 & 22 & $\mathrm{~K}>\mathrm{Mg}>\mathrm{Ca}>\mathrm{B}>\mathrm{Mn}>\mathrm{Cu}>\mathrm{P}>\mathrm{Zn}>\mathrm{N}>\mathrm{Fe}>\mathrm{S}$ \\
\hline 19 & 26 & -11 & -3 & 4 & -19 & -9 & 3 & 10 & 45 & -2 & -2 & -16 & 11 & $\mathrm{Ca}>\mathrm{Zn}>\mathrm{N}>\mathrm{Mg}>\mathrm{P}>\mathrm{Fe}>\mathrm{Mn}>\mathrm{S}>\mathrm{K}>\mathrm{B}>\mathrm{Cu}$ \\
\hline 20 & 36 & 12 & 9 & 15 & 6 & -2 & -29 & -2 & -10 & -4 & -1 & 6 & 9 & $\mathrm{~S}>\mathrm{Cu}>\mathrm{Fe}>\mathrm{Mg}>\mathrm{B}>\mathrm{Mn}>\mathrm{Ca}>\mathrm{Zn}>\mathrm{P}>\mathrm{N}>\mathrm{k}$ \\
\hline
\end{tabular}

Segundo Sumner (1977), quando se tem deficiência de vários nutrientes, a ordem de grandeza dos índices é que determinará o tratamento a ser aplicado para melhorar a produtividade dos vinhedos.

De acordo com esse sistema, também pode-se realizar estudos pelo Índice de Balanço Nutricional (IBN), que corresponde à soma dos valores absolutos dos índices DRIS de cada nutriente dividido pelo número de nutrientes estudados, que neste trabalho corresponde a 11 , sendo que, quanto menor o IBN ou mais próximo de zero, melhor o estado nutricional do vinhedo, de forma semelhante às observações de Sumner(1977a).

Cabe ressaltar o fato de ser comum um vinhedo com IBN adequado e até mesmo inferior aos dos vinhedos com produtividade alta apresentarem baixa produtividade, sugerindo melhor equilíbrio nutricional que os mesmos. Este fato sugere que a principal limitação na produtividade desse vinhedo é de ordem não nutricional, o que está de acordo com o afirmado por Snoeck (1984). A afirmação deste autor é que nem sempre uma planta em equilíbrio nutricional terá alta produtividade, sendo apenas o inverso verdadeiro, ou seja, alta produtividade só é alcançada quando as plantas estiverem em equilíbrio nutricional.

Outro dado que se pode obter através da calibração dos IBN são os seus valores que poderão ser usados como referência de equilíbrio nutricional para vinhedos da região em estudo (Tabela 8).

De acordo com os valores de referência obtidos, o limbo foi o órgão que apresentou enquadramento mais coerente, pois os valores de referência foram semelhantes para as três épocas estudadas, enquanto que os valores para pecíolo variaram muito de época para época. Baseado nesse fato, o valor do índice de balanço nutricional 11 pode ser considerado uma referência para vinhedos de alta produtividade.

Certas plantas, pela sua constituição morfológica, permitem facilmente a separação das folhas em pecíolo e limbo para fins de análise química. O pecíolo de algodoeiro, batatinha, tomateiro e videira tem apresentado concentração mais elevada de potássio do que o limbo (Silva et al., 1971; Gallo et al., 1965; Hiroce et al., 1972; Hiroce e Terra, 1984; Terra et al., 1998) e, portanto, constitui a parte da folha mais indicada para o estudo específico da nutrição potássica. Beattie e Forshey (1954) utilizaram pecíolo da folha madura mais nova para estudo da situação 
TABELA 8 - Índice de Balanço Nutricional (IBN) para limbos e pecíolos de uva 'Itália', em função de épocas de amostragem.

\begin{tabular}{|c|c|c|c|c|c|}
\hline \multirow[t]{2}{*}{ Amostra } & \multirow[t]{2}{*}{ Época } & \multicolumn{2}{|c|}{ Número de vinhedos } & \multicolumn{2}{|c|}{ IBN } \\
\hline & & Baixa produtividade & Alta produtividade & Adequado & Inadequado \\
\hline \multirow[t]{4}{*}{ Limbo } & Florescimento & 01 & 05 & $0-11$ & --- \\
\hline & Frvilha/meia-haga & 13 & 01 & -- & $>11$ \\
\hline & 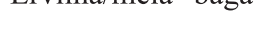 & $\begin{array}{l}01 \\
13\end{array}$ & $\begin{array}{l}00 \\
06\end{array}$ & $\begin{array}{l}0-8 \\
----\end{array}$ & $>8$ \\
\hline & Amolecimento & $\begin{array}{l}06 \\
08\end{array}$ & $\begin{array}{l}03 \\
03\end{array}$ & 0-11 & $>11$ \\
\hline \multirow[t]{3}{*}{ Pecíolo } & Florescimento & $\begin{array}{l}06 \\
08\end{array}$ & $\begin{array}{l}02 \\
01\end{array}$ & $\begin{array}{c}0-11 \\
----\end{array}$ & >--- \\
\hline & Ervilha/meia-baga & $\begin{array}{l}02 \\
12\end{array}$ & $\begin{array}{l}00 \\
06\end{array}$ & $\begin{array}{l}0-8 \\
---\end{array}$ & $>8$ \\
\hline & Amolecimento & $\begin{array}{l}04 \\
10\end{array}$ & $\begin{array}{l}04 \\
02\end{array}$ & $\begin{array}{c}0-10 \\
---\end{array}$ & $>10$ \\
\hline
\end{tabular}

nutricional de 56 vinhedos da cultivar Concord. Gallo e Oliveira (1960) utilizaram pecíolo mais limbo da folha madura mais nova da videira cultivar Angélica em diferentes estágios de desenvolvimento da planta. Hiroce e Terra (1984) determinaram os teores de macronutrientes em pecíolo e limbo, analisados separadamente, da folha recém-madura da videira cultivar Niagara Rosada, no estágio de chumbinho. Concluíram que no pecíolo houve concentrações mais elevadas de $\mathrm{K}$ e $\mathrm{Mg}$ e, no limbo, teores mais elevados de N, Ca e S. Em consequiência, concluíram que deve-se levar em conta ambas as partes da folha da videira para estudo da nutrição mineral.

Gergoletti (1995) e Costa (1998), avaliando o estado nutricional da videira 'Itália', respectivamente, nas regiões de São Miguel Arcanjo e Jundiaí, SP, usando o DRIS, concluíram que o limbo foi o órgão ideal de coleta.

As épocas mais adequadas para a amostragem de folhas foram no florescimento e no início do amolecimento das bagas, pelo fato da maior coerência dos índices de balanço nutricional adotados como referência.

Estes resultados são concordantes com os de Christensen et al. (1982), Gergoletti (1995) e Costa (1998) que afirmaram que a coleta do órgão para amostragem deve ser realizada no florescimento, e com os de Dal Bó (1992) que afirmou ser no início do amolecimento das bagas.

A partir da definição do melhor órgão e das melhores épocas de amostragem de folhas, procedeu-se ao estudo de cada vinhedo em particular, considerando-se apenas os dados de limbo coletados no florescimento e no início de amolecimento das bagas.

Observou-se que quando há nutrientes deficientes no balanço nutricional, a ordem de grandeza dos índices é que orientará a escolha dos melhores tratamentos, visando o aumento da produção, o que concorda com as observações feitas por Sumner (1977b).

Através da interpretação desses dados, verificou-se desordens nutricionais ligadas à deficiência dos macronutrientes potássio, fósforo, magnésio e enxofre. Quanto aos micronutrientes, as deficiências nutricionais foram pouco significativas. Desordens nutricionais ligadas à excesso, nos vinhedos selecionados, se deram para o nitrogênio quando se coletou folhas no estádio de florescimento e para o cobre nos estágios de florescimento e de início de amolecimento das bagas.

Diversos trabalhos mostraram vantagens do DRIS em relação ao nível crítico foliar para se fazer diagnose com o propósito de recomendação de complementação de adubação (Escano et al., 1981; Jones, 1981; Jones e Bowen, 1981; Hanson, 1981; Jones et al., 1986; Walworth e Sumner, 1987; Schaller, 1988), com as seguintes observações: (a) para se fazer diagnose considera-se o equilíbrio nutricional com base em padrões nutricionais de referência ou normas. Isto é particularmente importante em altos níveis de produção, em que o equilíbrio nutricional é muitas vezes o fator crítico na determinação da produtividade vegetal; (b) as normas, ou composição de referência para o equilíbrio nutricional de uma determinada cultura, podem ser extrapoladas para diversas regi- ões dos países; (c) pode-se fazer diagnoses em diferentes fases de desenvolvimento vegetal independentemente da cultivar; (d) os nutrientes limitantes da produção podem ser prontamente identificados e ordenados em função de sua importância na limitação da produtividade.

A importância do DRIS para a cultura da videira 'Itália' se dá, principalmente, pelo fato de ser uma cultura perene para a qual as desordens nutricionais afetam as plantas cumulativamente ao longo dos anos, além do fato destas correções de deficiência ou excesso, muitas vezes, não poderem ser feitas durante o ciclo da cultura, tornando a diagnose um fator fundamental no início do mesmo.

\section{CONCLUSÕES}

1) O limbo foi considerado o melhor órgão para amostragem de folhas.

2) Os estágios de florescimento e início de amolecimento das bagas foram consideradas as épocas mais adequadas para amostragem de folhas de videira.

3) De vinte vinhedos avaliados, seis foram considerados em equilíbrio nutricional, com produção superior à média de 27,3 t/ha e IBN igual a 11 .

4) O DRIS permitiu determinar os vinhedos que, em geral, apresentavam deficiência de potássio, fósforo, magnésio e enxofre, e excesso de cobre, principalmente.

\section{REFERÊNCIAS BIBLIOGRÁFICAS}

BATAGLIA, O.C. DRIS-Citros-Uma alternativa para avaliar a nutrição das plantas. Laranja, Cordeirópolis, v.10, n.2, p.565-576, 1989.

BATAGLIA, O.C; DECHEN, A.R. Critérios alternativos para diagnose foliar. In: SIMPÓSIO AVANÇADO DEQUÍMICA E FERTILIDADE DO SOLO, 1., 1986, Piracicaba, Anais... Campinas: Fundação Cargil, 1986. p.115-136.

BATAGLIA, O.C.; FURLANI, A.M.C.; TEIXEIRA, J.P.F.; FURLANI, P.R.; GALLO, J.R. Métodos de análise química de plantas. Campinas: IAC, 1983. 48p. (Boletim Técnico, 78).

BEATTIE, J.M.; FORSHEY, C.G. A survey of the nutrient element status of Concord grapes in Ohio. Proceedings of the American Society Horticultural Science, Alexandria. n. 64, p. 21-28, 1954.

BEAUFILS, E.R. Diagnosis and Recommendation Integrated System (DRIS). a General Scheme for experimentation and calibration based on principles developed from research in plant nutrition. Pietermaritzbarg, South África: University of Natal. 1973. 132p. Soil Science (Bulletin, 1).

CHRISTENSEN, L.P.; KASIMATIS, A.N.; JENSEN, F.L. Grapevine nutrition and fertilization in San Joaquim Valley. Berkeley: University of Califórnia, 1982. 40p. (Publication, 4087).

COSTA, F. Avaliação do estado nutricional da videira cultivar Itália em 
três estágios de desenvolvimento, na região de Jundiaí-SP, utilizando o método DRIS. 1998. 91f. Dissertação (Mestrado). Escola Superior de Agricultura "Luiz de Queiroz", Universidade de São Paulo, Piracicaba, 1998.

DAL BÓ, M.A. Nutrição e adubação da videira. Agropecuária Catarinense, Florianópolis, v.5, n.4, p.32-35, 1992.

ESCANO, C.R.; JONES, C.A.; VEHARA, G. Nutrient diagnosis in corn grow on Hydric Dystrandepts: II Comparition of two systems of tissue diagnosis. Soil Science Society American Journal, Madison, n.45, p.1140-1144, 1981.

GALLO, J.R.; COELHO, F.A.S.; NÓBREGA, S. de A. Análise de folíolos e pecíolos na diagnose da nutrição da batatinha. Bragantia, Campinas, v. 24, p. 385-401, 1965.

GALLO, J.R.; OLIVEIRA, A.S. Variações sazonais na composição mineral de folhas de videira e efeitos do porta-enxerto e da presença de frutos. Bragantia, Campinas, v. 19, p. 883-889, 1960.

GERGOLETTI, I.F. Avaliação do estado nutricional da videira 'Itália',em três estágios de desenvolvimento em São Miguel Arcanjo, SP, utilizando o método DRIS. 1995. 84f. Dissertação (Mestrado) Escola Superior de Agricultura "Luiz de Queiroz", Universidade de São Paulo, Piracicaba. 1995.

HANSON, R.G. DRIS evaluation of N, P, K status of the determinert soybeans in Brazil. Communications Soil Scinece Plant Analysis, New York, v.12, n.9, p.933-948, 1981.

HIROCE, R.; BATAGLIA, O.C.; GALLO, J.R.; CAMPOS, H.P. Amostragem em tomateiro (Lycopersicon esculentum Mill) cultivar Santa Cruz IAC-2731, para fins de análise química foliar. Ciência e Cultura, São Paulo, v. 24, n. 3, p. 242-244, 1972.

HIROCE, R.; TERRA, M.M. Teores de macronutrientes em pecíolo e limbo da videira 'Niagara Rosada'. In: CONGRESSO BRASILEIRO DE FRUTICULTURA, 7., 1983. Florianópolis. Anais... Florianópolis: SBF, 1984. v.4, p.1.184-1.187.

JONES, C.A. Proposed modifications of the diagnosis and reconmendation integrated system (DRIS) for interpreting plant analyses. Communications Soil Science Plant Analysis, New York, v.12, n.9, p.785-974, 1981.

JONES, C.A.; BOWEN, J.E. Comparative DRIS and crop log analysis diagnosis of sugarcane tissue analysis. Agronomy Journal, Madison, n.73, p.941-944, 1981.

JONES, M.B.; CENTER, D.M.; VAUGHN, C.E.; BELL, F.L. Using DRIS to assay nutrients in subclover. California Agricultural, Berkeley, n.40, p.19-21, 1986.

SCHALLER, K. Assessment of nutrient status of grapevines by leaf analysis in four P-fertilization studies with special regard to the DRIS system. Mitteilungen Klosterneuburg rebe und Wein, Obstbau und Fruchteverwertung, v.38, n.4, p.151-163, 1988. /Resumo em Horticultural Abstracts, v.58, n.11, p.920, Nov., 1988.

SILVA, N.M. da; HIROCE, R.; FUZATTO, M.G. Efeito da adubação sobre o desenvolvimento e a produção de duas variedades paulistas de algodoeiro, em Latossol Roxo intensamente cultivado. Campinas: Instituto Agronômico, 1971. 8p. (Projeto BNDE/ANDA/CIA, nº5).

SNOECK, J. Caféier. In: MARTIN-PRÉVEL, P.; GAGNARD, J.; GAUTIER, P. L'Analyse végétale dans le contrôle de l'alimentation des plantes. Paris: Techinique et Documentatin-Lavousier, 1984. p.473-495.

SUMNER, M.E. Application of Beaufils Diagnostic indices to maize data published in the literature irrespective of age and conditions. Plant and Soil., The Hague, n.46, p.359-369, 1977.

SUMNER, M.E. Preliminary NPK foliar diagnostic norms for wheat. Communications in Soil Science Plant Analysis, New York, v.8., n.2, p.149-167, 1977a.

SUMNER, M.E. Use of the DRIS system in foliar diagnosis of crops at high yield level. Communications in Soil Science Plant Analysis, New York, v.8, n.2, p.252-268, 1977b.

TERRA, M.M.; PIRES, E.J.P.; NOGUEIRA, N.A.M. Tecnologia para a produção de uva Itália na região noroeste do Estado de São Paulo. $2^{\text {a }}$ ed. Rev. atual. Campinas: Coordenadoria de Assistência Técnica Integral, 1998. 81p. (Documento Técnico, 97).

WALWORTH, J.L.; SUMNER, M.E. The diagnosis and recommendation integrated system. In: STEWART, B.A. Advances in Soil Science. New York: Springer - Verlag, 1987. p.150-188. 